\title{
Size dependent inhibition of sperm motility by copper particles as a path towards reversible male contraception
}

Purnesh Chattopadhyay, ${ }^{\dagger}$ Veronika Magdanz, ${ }^{\ddagger}$ Konstantin B. L. Borchert, ${ }^{\top}$ Dana Schwarz, "and Juliane Simmchen*,†

$\dagger$ †hysical Chemistry, TU Dresden, Zellescher Weg 19, 01069 Dresden, Germany $\ddagger$ Institute for Bioengineering of Catalonia (IBEC), Barcelona Institute for Science and Technology, Barcelona, Spain

\Leibniz-Institut für Polymerforschung Dresden e.V., Hohe Str. 6, 01069 Dresden, Germany

E-mail: juliane.simmchen@tu-dresden.de

Phone: +49351 463-37433

\begin{abstract}
Effective inhibition of sperm motility using a spermicide can be a promising approach in developing non-invasive male contraceptive agents. Copper is known to have contraceptive properties and has been used clinically for decades as intrauterine contraceptive devices (IUDs) for contraception in females. Beyond that, the spermicidal use of copper has not been explored much further, even though its use could also subdue the harmful effects caused by the hormonal contraceptive agents on the environment. Herein, we study the size, concentration and time dependent in vitro inhibition of bovine spermatozoa by copper microparticles. The effectivity in inhibiting the sperm
\end{abstract}


motility is correlated to the amount of $\mathrm{Cu}^{2+}$ ions released by the particles during incubation. The copper particles cause direct suppression of sperm cell motility upon incubation and thereby show potential as sperm inhibiting, hormone free candidate for male contraception beyond condoms.

\section{Introduction}

Regulation of fertility and reproduction is one of the main targets in the human health sector, with egalitarian access to effective contraception means for males ${ }^{1}$ and females moving further to the public attention. Even in the 21st century, the female-only contraception methods dominate the market: female sterilization, intrauterine devices, hormonal treatment through oral, injectable and implant administration. ${ }^{2}$ Some of these methods are invasive and associated to health problems, for instance, hormonal birth control in women are reported to have mild to severe side effects. ${ }^{3}$ In the male contraceptive sector there has not been much advancement besides barrier methods and vasectomy. ${ }^{1,4}$ Despite growing demand on the market, only around $30 \%$ of couples use a form of male contraception. Lately, efforts in the development of hormonal contraception for men have increased, but many have been associated with side effects and social stigma, so they have yet to be approved. Hormonal approaches are divided into administration of pure androgens, combinations of testosterone with progestogens and combinations with gonadotropin-releasing hormone antagonists, ${ }^{5}$ all showing potential as male contraceptives, but longevity and reversibility of action still have to be improved. ${ }^{6}$

Besides the medical drawbacks of hormonal contraception, the drastic effects on the environments have to be considered. The release of hormones into waste water and finally exposure to aquatic life has shown to alter aquatic ecology. ${ }^{7-10}$ Both estrogens and progestins have been considered as a potent endocrine disrupters for both humans and aquatic lives even at a very low concentrations (as low as ng $\mathrm{L}^{-1}$ ). ${ }^{10-12}$ At lower concentrations it causes ineffective reproduction or feminization of male fishes, and chronic exposure can even lead to extinc- 
tion of a fish population. ${ }^{9}$ Further, these hormones or their metabolites are very resistant to biodegradation and show high removal inefficiencies. ${ }^{13}$ Thus, the focus of contraceptive research toward a more sustainable approach is a viable strategy to restrain the overuse of these hormonal means.

The efficacy of the contraceptive methods is also an important parameter to consider. These efficacy rates can be measured in terms of the pearl index which calculates unintended pregnancies in 100 women in a year of exposure. Male condoms have a pearl index of $2.5-5.9$ which is higher compared to methods such as intrauterine devices (IUDs) for females $(0.16$ -1.26). ${ }^{14}$ Therefore, prospective male contraceptives will only be impactful if they provide improved efficacy.

The development of a contraceptive that completely ceases the hyperactivation or motility of the sperm cells and avoids the crossing of "blood-testis" barrier has been envisioned as a promising approach in the advancement of future male contraception. ${ }^{4,15}$ As a drug, they can be used as injectables, ${ }^{16,17}$ where they stay within the seminal fluids and are ejaculated along with the sperms, or if they have an immediate response, they can be even administered just before the intercourse as component of gels or condoms. ${ }^{4}$ Here, we demonstrate the suitability of copper as such motion inhibiting agent, bypassing the environmentally critical use of hormones.

The earliest reference of inhibition by cupric ions on mammalian spermatozoa was carried out by de Quatrefages in 1850. ${ }^{18}$ Later, further effects of copper in reproductive processes have been investigated. ${ }^{19,20}$

On the one side, copper is a nutritional trace element required for hemoglobin formation, ${ }^{21}$ maintaining health of embryos and also involved in the ovulation process. ${ }^{22}$ On the other side, copper in excess concentration $\left(>62.5 \mu \mathrm{M}\right.$ concentration of $\mathrm{Cu}^{2+}$ ions $\left.{ }^{23}\right)$ can cause infertility or inhibition of reproductive processes. ${ }^{24}$ As an inhibitor, copper affects spermatozoa motility, ${ }^{25}$ by suppressing metabolic processes such as glucose consumption and oxidative processes of sperm cells. ${ }^{23,26}$ Besides, the $\mathrm{Cu}^{2+}$ ions released from $\mathrm{Cu}$ form copper chelation 
complexes with mucoids which can curb spermatogenesis. ${ }^{23,24}$ Additionally, when present in the genital tract, it can induce inflammatory responses which are toxic for spermatozoa and embryos. ${ }^{27}$ The main spermicidal action of copper can be attributed to the metabolic and kinetic inhibition of spermatozoa, as found in several other heavy metals as well.

These spermicidal effects of copper in reproductive processes allowed the clinical development of Cu-IUDs in the early 1920s, with Ernst Gräfenberg as one of the pioneers whose work is believed to have led to the first copper compounds in these devices (introduced through a silver wire). ${ }^{28}$ Following that, Zipper et al., in 1969 demonstrated the use of copper spirals in plastic IUDs. ${ }^{29,30}$ These $\mathrm{Cu}$ wires locally excrete low concentrations of copper ions in the uterus and inhibit sperm survival after entering the female reproductive tract. ${ }^{31}$ It is now proven to be an effective, non-hormonal, reversible female contraception method and is being widely used since 1970s. ${ }^{32,33}$ Safety of such devices is evaluated via apoptosis levels in surrounding tissues. These showed no increase in endometrial tissue after exposure to Copper IUDs and is thus considered safe. ${ }^{34}$ Disadvantages include disruptions in the menstrual cycle and post-surgical pain and bleeding and implantation involves a small surgery. Therefore, this method is not widely recommended for all women. ${ }^{24}$

Due to its compelling effectiveness and the absence of hormonal residues and metabolites in waste water, the use of $\mathrm{Cu}$ in male contraception also gained experimental implications. ${ }^{35}$ The group of Kapur and Laumas developed the intravasal $\mathrm{Cu}$ (IVDs) which are inserted in the vas deferens and can be used as effective and reversible method for male contraception. ${ }^{36,37}$ Through many other research programs, the implantation of copper devices in the male reproductive system also included: the lumen of the ductus deferens, epididymis, scrotum, etc. ${ }^{26}$ The biggest concern is the direct implantation of these Cu-IVDs in the scrotum and vas deferens created toxicological effect on the tissues. ${ }^{38}$ The development of copper in effective and non-invasive male contraceptive is yet to be accomplished.

Micro- or nanoscience has evolved as a remarkable tool in biomedical applications. ${ }^{39,40}$ The use of micro- or nanoparticles is more advantageous than their bigger conjugates due 
to their high surface-to-volume ratio and their additional intrinsic properties. ${ }^{41}$ The photothermic or magnetothermic effect of metal or metal-oxide nanoparticles has been explored as a reversible, non-surgical method for male contraception. ${ }^{42,43}$ However, all these methods involve intravenous administration and testicular hyperthermia might damage the testicles and permanently suppress the spermatogenesis process. ${ }^{44,45}$

Besides a variety of catalytic applications, ${ }^{46}$ copper micro- or nanoparticles are being used as a biocidal agents for the reduction and elimination of microbes. ${ }^{47}$

In this manuscript, the contraceptive effect of copper microparticles on bovine spermatozoa is explored. Copper particles of three different sizes are synthesized according to a recently developed strategy ${ }^{46}$ and their effect on the overall sperm motility and velocity is investigated (see Figure 1). To demonstrate a dependence on concentration, the release of $\mathrm{Cu}^{2+}$ ions is estimated by spectrophotometric and ICP-OES methods.

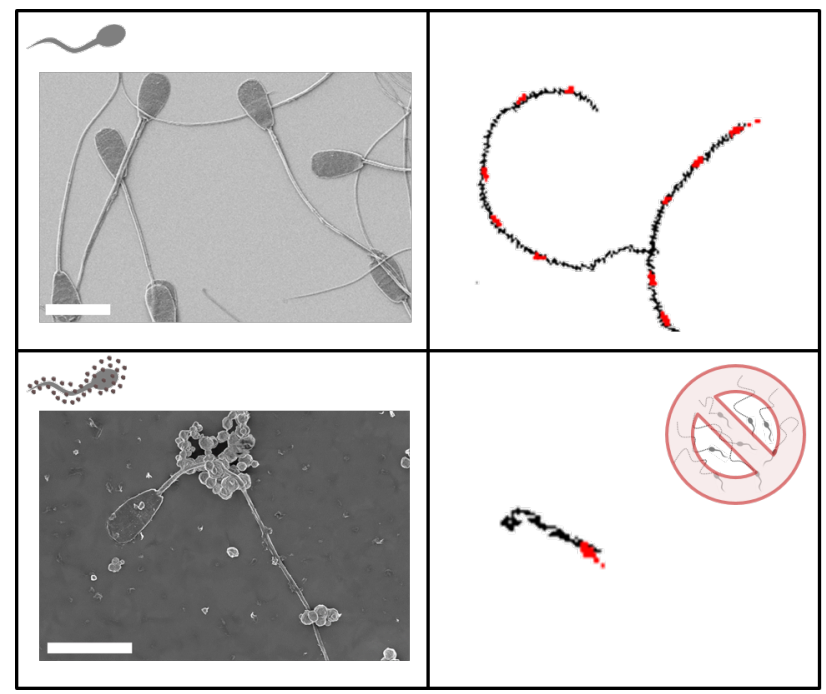

Figure 1: Exemplary SEM images of bovine spermatozoa in the absence and presence of copper microparticles $\left(\mathrm{Cu}_{2}\right.$ particles) with the following example track is shown in the upper and lower panel respectively. The tracks represent the motion of sperm cells in sperm medium (control) and in presence of $0.1 \mathrm{~g} \mathrm{~L}^{-1} \mathrm{Cu}_{2}$ particles in sperm medium, incubated for 15-30 minutes. The tracks are tracked for 220 frames $(5.5 \mathrm{~s})$. Scale bar: $10 \mu \mathrm{m}$. 


\section{Experimental Section}

\section{Materials and methods}

TL-Sperm (Caisson Labs, USA), sodium pyruvate (100 mM, Gibco, Thermofisher, Germany), gentamicin sulfate (Cassion labs, USA), bovine serum albumin (Sigma Aldrich, Germany) was purchased and used without any purification. Straws of cryo-preserved bovine semen (Masterrind GmbH, Meißen, Germany) was stored in liquid $\mathrm{N}_{2}$ until use.

$\mathrm{CuSO}_{4}$ (Reagent Plus, $\geq 99 \%$ ), $\mathrm{H}_{3} \mathrm{BO}_{3}$ ( $\left.\geq 99.5 \%\right), \mathrm{H}_{3} \mathrm{PO}_{4}(85 \%)$, and $\mathrm{HNO}_{3}(65 \%)$ was obtained from Sigma Aldrich, Germany. $\mathrm{CH}_{3} \mathrm{COOH}(100 \%)$ was obtained from VWR, Germany and polyethylenimine (M.Wt - 10000) from Polysciences, Germany.

We selected three different sized copper particles in the range 0.1 to $0.3 \mu \mathrm{m}$ labeled as $\mathrm{Cu}_{0.2}$, 1 to $2 \mu \mathrm{m}$ labeled as $\mathrm{Cu}_{2}$ and 6 to $7 \mu \mathrm{m}$ labeled as $\mathrm{Cu}_{7}$ (see Figure 2). The preparation of $\mathrm{Cu}_{0.2}$ and $\mathrm{Cu}_{7}$ is shown elsewhere. ${ }^{46} \mathrm{Cu}_{2}$ particles are formed by solvothermal synthesis described in detail in SI. The particles were characterized using XRD (Bruker D2 phaser diffractometer) and SEM (Zeiss DSM 982 GEMINI electron microscope).

\section{Preparation of sperm medium (SP-TALP)}

SP-TALP is a sperm specific medium, it is a tyrode's modified albumin lactate pyruvate medium. In a preparation of $10 \mathrm{~mL}$ SP-TALP, $9.5 \mathrm{~mL}$ of TL-Sperm is taken and it is supplemented with $500 \mu \mathrm{L}$ of sodium pyruvate $(100 \mathrm{mM}), 50 \mu \mathrm{L}$ of gentamicin sulfate and $60 \mathrm{mg}$ of bovine serum albumin. The medium was kept at $37^{\circ} \mathrm{C}$ prior to the motility assay.

\section{Sperm preparation}

A straw of bovine semen was taken out from cryogenic storage and quickly thawed in a water bath $\left(\right.$ at $37^{\circ} \mathrm{C}$ ) for 2 minutes. The straw was emptied in a $1.5 \mathrm{~mL}$ eppendorf tube and to it $500 \mu \mathrm{L}$ of SP-TALP was added. The sperm sample was then washed by centrifuging at 100 $\mathrm{g}$ for 7 minutes. The supernatant was removed and the washing was continued two more 
times. Finally, the sperm pellet was resuspended in $500 \mu \mathrm{L}$ of SP-TALP and kept in the incubator at $37^{\circ} \mathrm{C}$.

\section{Sperm-particle interaction}

The synthesized $\mathrm{Cu}$ particles were added in SP-TALP in a concentration of $2 \mathrm{mg} \mathrm{mL}^{-1}$ (stock $\mathrm{Cu}$ particle solution). The samples were sonicated for 10 minutes to properly disperse the particles. They were kept in the incubator at $37^{\circ} \mathrm{C}$ for at least 30 minutes before starting the experiments. The stock solution of $\mathrm{Cu}$ particles $\left(2 \mathrm{mg} \mathrm{mL}^{-1}\right)$ was diluted with sperm cells to make $0.1 \mathrm{mg} \mathrm{mL}^{-1}, 0.5 \mathrm{mg} \mathrm{mL}^{-1}$ and $1 \mathrm{mg} \mathrm{mL}^{-1}$ solutions. A control sample was also prepared without any $\mathrm{Cu}$ particles. The dilutions are shown in Table 1.

Table 1: Dilution table for preparation of required concentrations of $\mathrm{Cu}$ particles

\begin{tabular}{cccc}
\hline $\begin{array}{c}\text { Concentration of } \\
\text { particles }\left(\mathrm{mg} \mathrm{mL}^{-1}\right)\end{array}$ & $\begin{array}{c}\text { Amount of stock } \mathrm{Cu} \\
\text { particle solution }(\mu \mathrm{L})\end{array}$ & $\begin{array}{c}\text { Amount of } \\
\text { Sperm }(\mu \mathrm{L})\end{array}$ & $\begin{array}{c}\text { Amount of } \\
\text { SP-TALP }(\mu \mathrm{L})\end{array}$ \\
\hline 0 & 0 & 50 & 50 \\
0.1 & 5 & 50 & 45 \\
0.5 & 25 & 50 & 25 \\
1.0 & 50 & 50 & 0 \\
\hline
\end{tabular}

\section{Sperm motility assay}

To understand the influence of the particles on sperm cells, the total amount of motile cells (motility) and velocity of the sperm cells were characterized using an inverted microscope (Axio observer, Carl Zeiss Microscopy $\mathrm{GmbH}$ ) and recorded with an attached Zeiss camera (Axiocam 702 Mono). The movies were recorded at a frame rate of $40 \mathrm{fps}$ for at least 200 frames with 10x magnification. After incubating the $\mathrm{Cu}$ particles with spermatozoa, videos were taken after every 15 minutes time range for 3 distinct intervals marked as $\mathrm{I}^{\text {st }}, \mathrm{II}^{\text {nd }}$ and III $^{r d}$. The time range for $\mathrm{I}^{s t}, \mathrm{II}^{n d}$ and III $^{r d}$ time intervals are 0 - 15 minutes, 15 - 30 minutes and 30 - 45 minutes respectively. The data is obtained for every case by evaluating 4-5 videos 
with at least 200 sperm cells. Statistical treatment was performed on the motility with a oneway ANOVA with Bonferroni method (in Origin). To maintain an equivalency within the results, control samples were correspondingly measured in parallel to every particle inhibition case and from the same straw of semen.

\section{Motion analysis}

The videos were analyzed using ImageJ software with CASA plugin. ${ }^{48}$ With the help of this plugin, we calculated the motility of the sperm cells which is given as the ratio of number of motile sperms to the total number of sperms:

$$
\% \text { Motility }=\frac{\text { Number of motile sperms }(\mathrm{N})}{\text { Total number of sperms }\left(\mathrm{N}_{0}\right)} * 100 \%
$$

The velocity of the sperm cells is calculated in multiple modes. ${ }^{49}$ Here we took into account the three different velocities: The curvilinear velocity (VCL), the straight line velocity (VSL) and the average path velocity (VAP) obtained directly from the plugin. ${ }^{48}$ Statistical treatment on VCL for Figure 4 was performed with a one-way ANOVA with Bonferroni method (in Origin).

\section{Detection of $\mathrm{Cu}^{2+}$ ions by spectrophotometry}

The spectrophotometric determination of cupric ions was commenced following the literature. $^{50}$

\section{Preparation of samples:}

$\mathrm{Cu}_{0.2}, \mathrm{Cu}_{2}$, and $\mathrm{Cu}_{7}$ were each added to a vial, containing either DI-water or SP-TALP to make the final concentration to $5 \mathrm{~g} \mathrm{~L}^{-1}$. The mixture was sonicated for 30 minutes and kept overnight to make the dissolved ions be in equilibrium with the medium. On the following day, the sample mixture was centrifuged and the supernatant was taken for further use. Next, the supernatant was diluted with PEI, buffer, water and SP-TALP to make a final 
concentration of $0.1 \mathrm{~g} \mathrm{~L}^{-1}$.

\section{General procedure for analysis:}

Stock solutions of $0.1 \mathrm{M}$ copper (II) sulfate, $9.4 \mathrm{mg} \mathrm{mL}^{-1}$ Polyethylenimine (PEI) and Britton-Robinson (BR) buffer of $\mathrm{pH} 6$ were prepared. The buffer solution was prepared by mixing $0.04 \mathrm{M}$ each of $\mathrm{H}_{3} \mathrm{PO}_{4}, \mathrm{H}_{3} \mathrm{BO}_{3}$ and $\mathrm{CH}_{3} \mathrm{COOH}$, the $\mathrm{pH}$ was then adjusted by $0.2 \mathrm{M}$ $\mathrm{NaOH}$ solution. The analysis was done in DI-water and SP-TALP for each case separately.

For water, $30 \mu \mathrm{L}$ of PEI was added from the stock to make the final concentration of the solution $0.094 \mathrm{mg} \mathrm{mL}^{-1}$, then $600 \mu \mathrm{L}$ of BR buffer was added. Subsequently different volumes of $0.1 \mathrm{M} \mathrm{CuSO}_{4}$ were added to make the $\mathrm{Cu}$ concentration 0 to $500 \mu \mathrm{M}$. The mixture was diluted with DI-water to make the final volume to $3 \mathrm{~mL}$. For SP-TALP, the same procedure was followed, just the volume of the measuring samples is adjusted with SP-TALP.

The UV absorption spectra are measured using Cary 50 Scan UV-Visible spectrophotometer in the range 200 to $800 \mathrm{~nm}$ using a $1 \mathrm{~cm}$ path length quartz cuvette.

\section{Detection of $\mathrm{Cu}^{2+}$ ions by ICP-OES method}

Inductively coupled plasma optical emission spectrometry (ICP-OES) (iCAP 7400 from Thermo Scientific, Waltham, USA) was used to determine the copper concentration. Initially, 8 standards were prepared by diluting a solution containing $10000 \mathrm{mg} \mathrm{L}^{-1}$ copper in $2 \mathrm{M} \mathrm{HNO}_{3}$ (Bernd Kraft, Duisburg, Germany). The respective copper concentrations of the standards were $500 \mathrm{mg} \mathrm{L}^{-1}, 100 \mathrm{mg} \mathrm{L}^{-1}, 50 \mathrm{mg} \mathrm{L}^{-1}, 10 \mathrm{mg} \mathrm{L}^{-1}, 5 \mathrm{mg} \mathrm{L}^{-1}, 1 \mathrm{mg} \mathrm{L}^{-1}$, $0.5 \mathrm{mg} \mathrm{L}^{-1}$, and $0.1 \mathrm{mg} \mathrm{L}^{-1}$. From the fivefold measurement of all standards, a calibration curve was constructed. The given detection limit was calculated by the software QtegraTM from Thermo Scientific with $0.02 \mathrm{mg} \mathrm{L}^{-1}$. The concentration of every sample was determined fivefold.

For the experiment, $8 \mathrm{mg}$ of $\mathrm{Cu}$ particles $\left(\mathrm{Cu}_{0.2}, \mathrm{Cu}_{2}\right.$, and $\left.\mathrm{Cu}_{7}\right)$ were taken in a vial and $7.68 \mathrm{~mL}$ of DI-water or SP-TALP was added to each of them. The mixture was sonicated for 30 minutes and kept overnight for maximum dissolution of $\mathrm{Cu}^{2+}$ in solution. After that, the 
sample was centrifuged and the supernatant was collected. Next, $1.32 \mathrm{~mL}$ of conc. $\mathrm{HNO}_{3}$ was added to the supernatant, to make the final concentration $890 \mathrm{mg} \mathrm{L}^{-1}$. The solution was further filtered with $2 \mu \mathrm{m}$ nylon syringe filter to obtain a clean solution without any turbidity. Similarly, two control samples of just DI-water and SP-TALP were also measured.

For both these methods, the detected amount of $\mathrm{Cu}^{2+}$ ions is evaluated by the percentage of $\mathrm{Cu}^{2+}$ ions released in the medium from the initial starting concentration, elaborately detailed in SI (section S5).

\section{Results \& Discussion}

\section{Characterization of copper particles}

To study the sperm inhibition effect by differently sized particles, we synthesized copper particles of three different size ranges via an assisted polyol reaction approach: smaller particles of $0.2 \mu \mathrm{m}\left(\mathrm{Cu}_{0.2}\right)$, medium-sized particles $\left(\mathrm{Cu}_{2}\right)$ and larger particles $\left(\mathrm{Cu}_{7}\right)$ (Figure $2 \mathrm{~A}, \mathrm{~B}$, and $\mathrm{C})$.

An additive-facilitated polyol method is employed to synthesize the $\mathrm{Cu}_{0.2}$ and $\mathrm{Cu}_{7}$ particles where simultaneous competing nucleation leads to the formation of copper microparticles in different size ranges. ${ }^{46} \mathrm{Cu}_{2}$ particles are synthesized by a simple hydrothermal method using ascorbic acid as a stabilizer and reducing agent.

The X-ray diffraction pattern (Figure 2D) of these particles exhibit similar reflexes attributing to metallic copper. These reflexes comply very well with the standard face-centered cubic phase of copper (JCPDS No. 040836) and the sharp reflexes depict the crystalline nature of samples.

Although these copper particles have positive surface charges (see Table S1), we did not observe any significant charge based interaction with the sperm cells like positively charged $\mathrm{Fe}_{2} \mathrm{O}_{3}$ particles, ${ }^{51}$ or IRONSperm. ${ }^{52}$ 

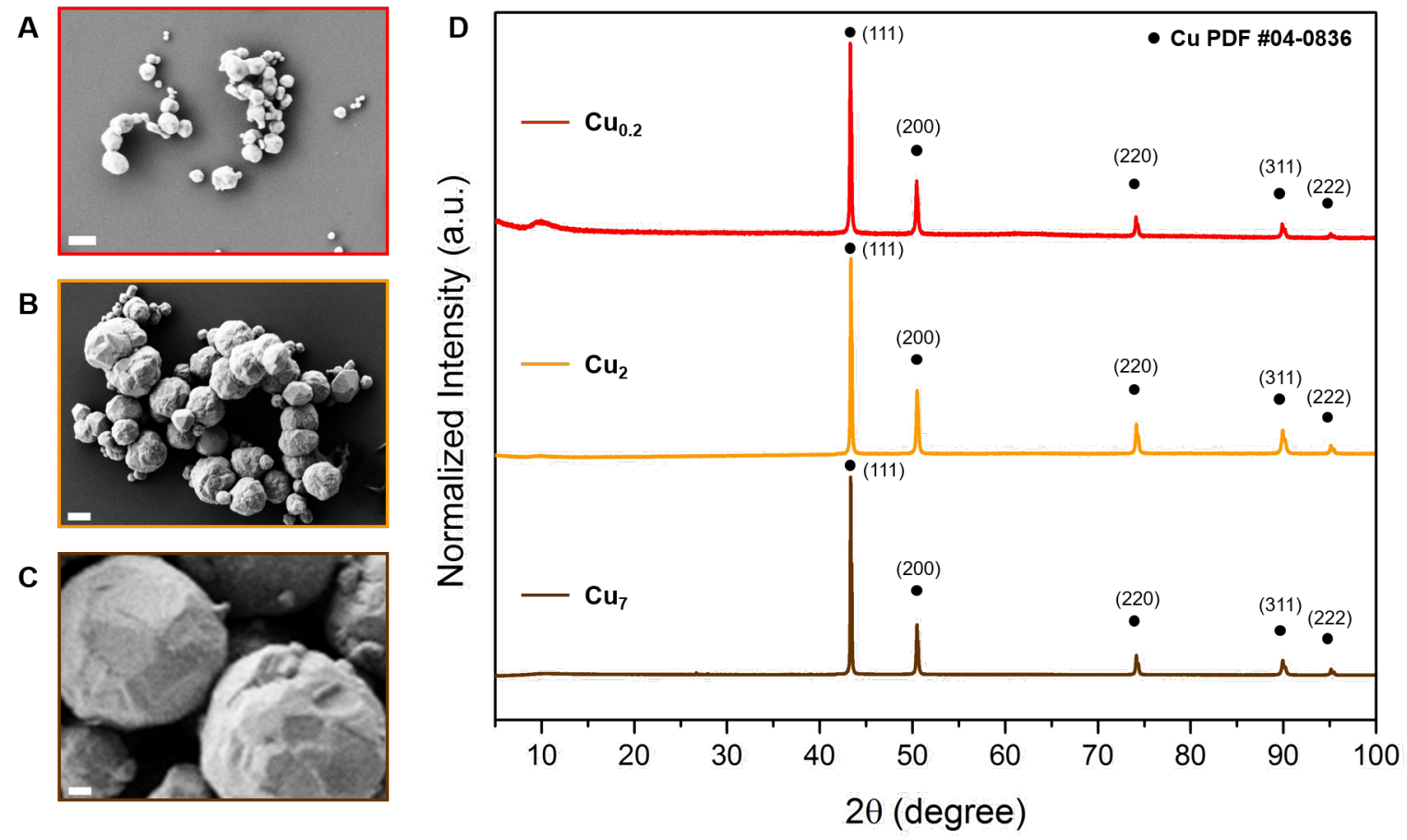

Figure 2: Characterization of the copper particles: SEM images of (A) $\mathrm{Cu}_{0.2}$ (B) $\mathrm{Cu}_{2}$ and (C) $\mathrm{Cu}_{7}$ particles. Scale bar: $1 \mu \mathrm{m}$. (D) XRD reflexes of $\mathrm{Cu}_{0.2}, \mathrm{Cu}_{2}$ and $\mathrm{Cu}_{7}$ particles, compared the standard FCC phase of $\mathrm{Cu}$.

\section{Amount of copper ions released in aqueous media}

As mentioned earlier, $\mathrm{Cu}^{2+}$ ions cause alterations in metabolic properties and are responsible for the immobilization of sperm cells. ${ }^{53,54}$ At higher concentrations, copper ions decrease the mitochondrial activity of the sperm cells, ${ }^{23}$ and can further inhibit the the acrosomal reaction between the male and female gametes. ${ }^{55}$

The toxic action of these cupric ions on the sperm cells is extensively influenced by the concentration of ions in the sample solution. ${ }^{23,54}$ Therefore, the amount of $\mathrm{Cu}^{2+}$ ions released from differently sized colloidal microparticles is investigated which supported the size-dependent effect on sperm cells.

To quantify and compare the amount of $\mathrm{Cu}^{2+}$ ions liberated by these differently sized particles, spectrophotometry and ICP-OES as two different approaches were used (detailed in the experimental section). From both methods, the percentage of $\mathrm{Cu}^{2+}$ ions released from a known amount of copper particles was calculated and compared for DI water and sperm 
A

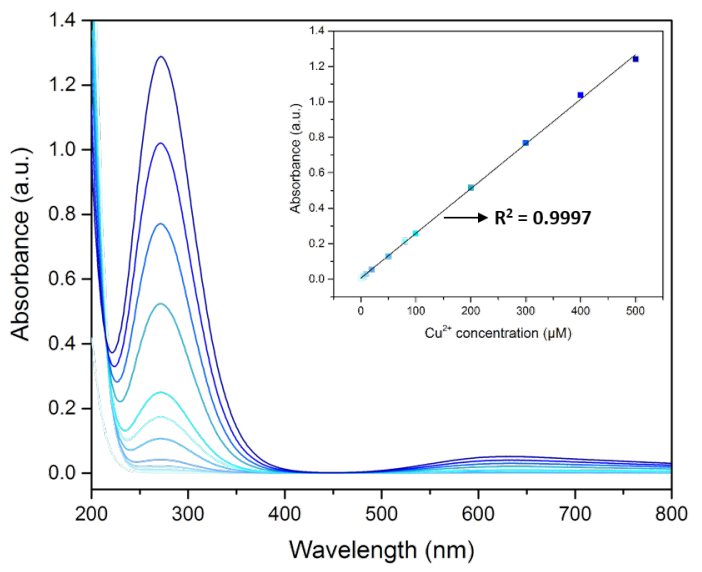

B

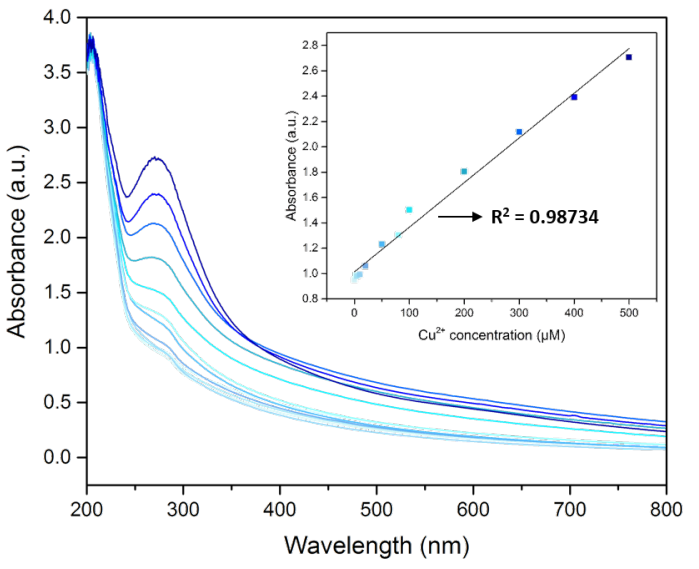

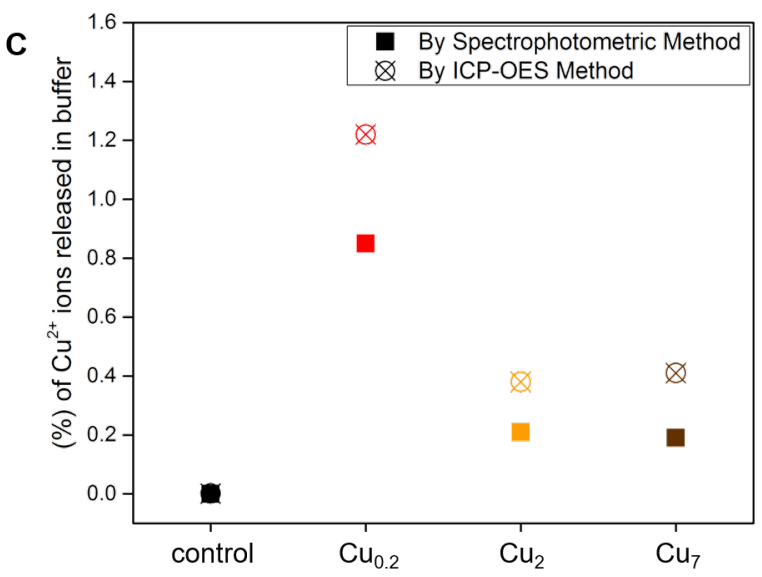

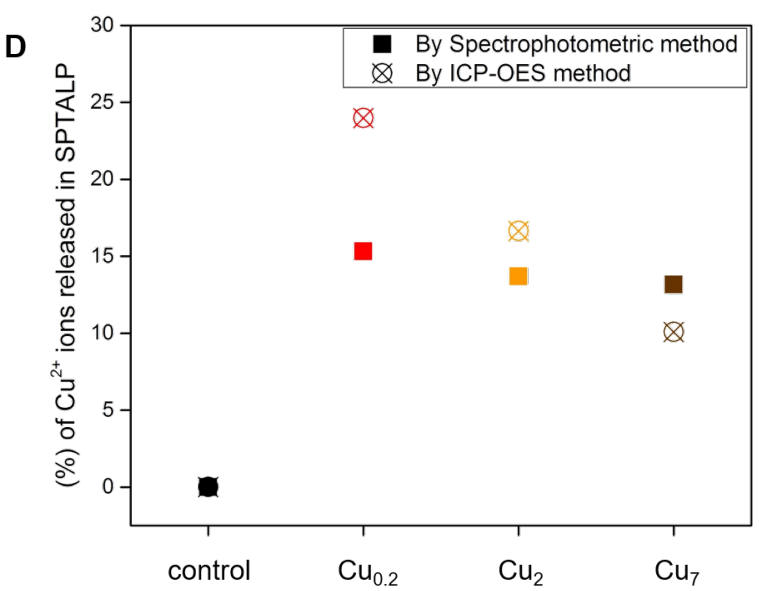

Figure 3: Detection of $\mathrm{Cu}^{2+}$ ions: Absorbance spectra of PEI in presence of different concentration $\mathrm{Cu}^{2+}$ ions $(0$ to $500 \mu \mathrm{M})$ for spectrophotometric determination in (A) DI-Water and (B) SP-TALP. The inset displays the $\mathrm{Cu}^{2+}$-PEI complex absorbance vs $\mathrm{Cu}^{2+}$ ions concentration $(0$ to $500 \mu \mathrm{M})$. The percentage of cupric ions released from differently sized copper samples by spectrophotometry and ICP-OES is compared in (C) DI-Water and (B) SP-TALP.

medium (SP-TALP).

In the spectrophotometric method, a complexation reaction between a cationic polymer polyethyleneimine (PEI) and $\mathrm{Cu}^{2+}$ ions was utilized. ${ }^{50,56}$ The resulting Cu-PEI moiety showed an absorbance peak at $275 \mathrm{~nm}$ and a significantly lower absorbance at $630 \mathrm{~nm}$ in aqueous medium. Initially, the absorbance spectra were plotted with a known concentration of $\mathrm{Cu}^{2+}$ ions $(0$ to $500 \mu \mathrm{M})$ in water (Figure 3A) and SP-TALP (Figure 3B). The absorbance at $275 \mathrm{~nm}$ for these spectra were plotted against $\mathrm{Cu}^{2+}$ ions concentrations $(\mu \mathrm{M})$ and a calibration curve was obtained in both, water and SP-TALP (see inset of Figure 3A and B). 
For both these media, the absorption intensity shows a linear positive correlation with $\mathrm{Cu}^{2+}$ ions concentration. But, in the case of SP-TALP, the transition from lower to higher wavelength, and the attained absorbance maxima were much greater than that observed in the case of DI water. As the SP-TALP is composed of different bases, phosphates, hydrocarbons, proteins, and minerals, there is a possibility of complexation of these medium constituents with the cationic polymer PEI, leading to these absorption discrepancies.

A quantitative measurement of the copper ion concentration for different sized particles was obtained from ICP-OES analysis.

Since the starting concentrations (in $\mathrm{g} / \mathrm{L}$ ) of the particles in both methods were different, we estimated the percentage of $\mathrm{Cu}$ ions released from a given amount of particles to make a uniform comparison (see SI, section S5). Figure 3C and D show the percentage of $\mathrm{Cu}^{2+}$ ions released in aqueous and SP-TALP respectively for different size ranges of copper particles. The trend in the amount of $\mathrm{Cu}^{2+}$ ions released by both methods was found to be similar. However, it is interesting to note that the amount of $\mathrm{Cu}^{2+}$ ions released in water is much lower compared to SP-TALP, for instance in case of $\mathrm{Cu}_{0.2}$ particles, by ICP-OES method a maximum of $1.22 \%$ was determined in water as compared to $23.95 \%$ release in SP-TALP. This is probably due to the presence of proteins and bases in the SP-TALP which favors dissolution by complexation of metal ions. As expected, a clear decrease in the amount of $\mathrm{Cu}^{2+}$ ions released with a surge in particle size is observed. This reduction is not so prominent in case of SP-TALP, when quantifying the $\mathrm{Cu}^{2+}$ ions using spectrophotometry. Whereas a significant decrease of $\mathrm{Cu}_{0.2}$ ions percentage is observed using the ICP-OES. This discrepancy can be explained by the possible complexation of PEI and SP-TALP and the resulting error associated with the spectrophotometric analysis in SP-TALP. The ICP-OES gives more accurate and reliable results. 


\section{Evaluation of spermatozoa motility in presence of $\mathrm{Cu}$ particles in SP-TALP}

The effect of differently sized copper particles in the inhibition of sperm cells is studied by evaluating the motility and the velocity of the sperm cells under varying particle concentrations and incubation time. Particle concentrations of $0.1 \mathrm{~g} \mathrm{~L}^{-1}, 0.5 \mathrm{~g} \mathrm{~L}^{-1}$ and $1 \mathrm{~g} \mathrm{~L}^{-1}$ were used and these tests were conducted over three time intervals of 15 minutes each (see "sperm motility assay" in experimental section). As time progressed, the number of motile sperm cells decreased, so to maintain homogeneity in the measurement results, a control sample (without the $\mathrm{Cu}$ particles) was also measured at every interval. This incubation period was estimated over time intervals and not exact time (in minutes) because, as there is a control sample alongside the $\mathrm{Cu}$ incubated sample, studying the motion of one sample in microscope changes the incubation time for the other, so it is preferable to indicate a time interval within which these studies were conducted.

Figure $4 \mathrm{~A}, \mathrm{~B}$, and $\mathrm{C}$ shows the average overall motility in percentage of sperm cells after incubating with $0.2 \mu \mathrm{m}, 2 \mu \mathrm{m}$, and $7 \mu \mathrm{m}$ particles respectively. Similarly, in Figure 4D, E, and $\mathrm{F}$ the average curvilinear velocity (VCL) is plotted for the same.

The mean percentage of motile spermatozoa is compared by altering the incubation conditions. The motility of sperm cells in presence of $\mathrm{Cu}_{0.2}$ particles within the $\mathrm{I}^{\text {st }}$ interval (0-15 minutes) drops to around $11 \%$ ( $89 \%$ of the sperm population was immotile) from its control value with particle concentration as low as $0.1 \mathrm{~g} \mathrm{~L}^{-1}$. The motility further drops to less than $5 \%$ from its control value in the following interval (within 15-30 minutes). The percentage of motile sperm finally drops to zero at the higher interval (30-45 minutes). For higher concentrations, no motile sperms were found and just to indicate the experimental existence, a column bar in the negative direction is plotted (see Figure 4A)

With the increasing $\mathrm{Cu}$ particle size (see Figure 4B), the effect on sperm motility changes. Analogous to the $\mathrm{Cu}_{0.2}$ particles, the motility of the sperm cells decreases with rise in the concentration of the $\mathrm{Cu}_{2}$ particles but the rate of decrease is much slower compared to 


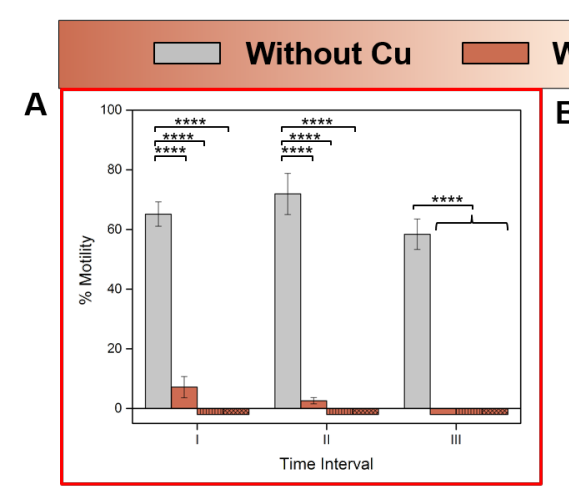

With $0.1 \mathrm{~g} / \mathrm{L} \mathrm{Cu}$

With $0.5 \mathrm{~g} / \mathrm{L} \mathrm{Cu}$

With $1 \mathrm{~g} / \mathrm{L} \mathrm{Cu}$

D
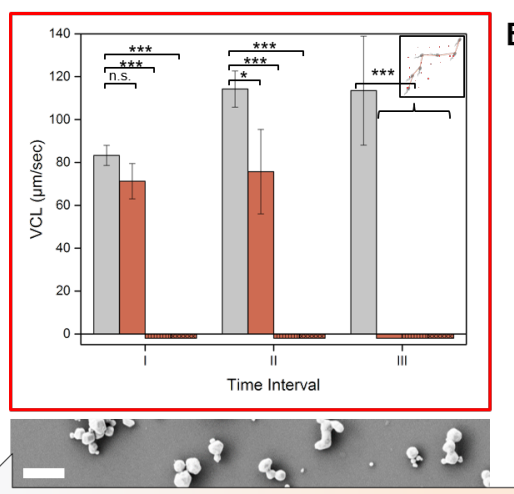

Most Effective
B

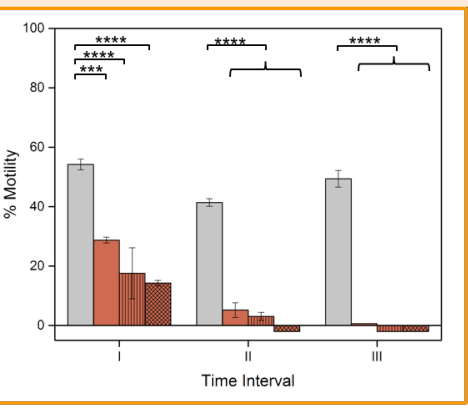

$\mathrm{E}$

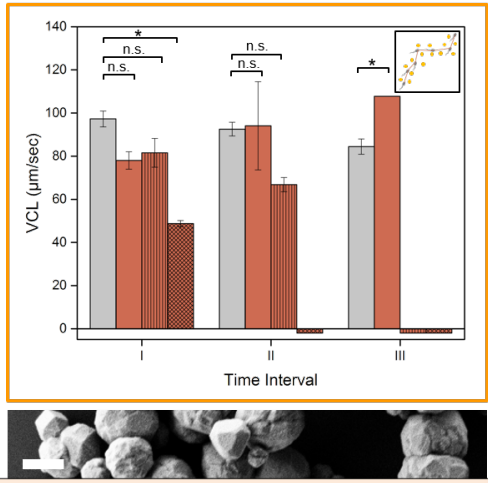

I.
C
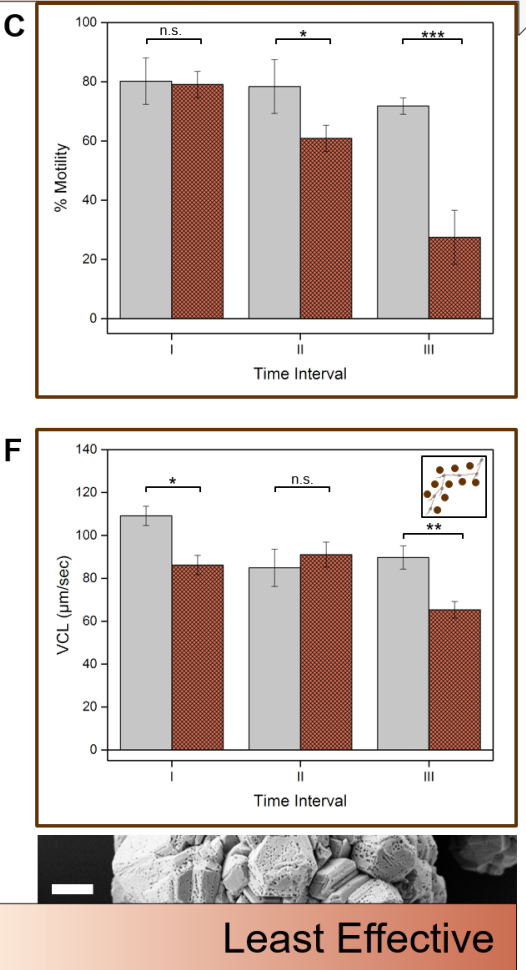

Figure 4: Average motility and curvilinear velocity (VCL) of sperm cells in comparison to a control post-incubation over three time intervals with (A \& D) $\mathrm{Cu}_{0.2}$, (B \& E) $\mathrm{Cu}_{2}$, and $(\mathrm{C} \& \mathrm{~F}) \mathrm{Cu}_{7}$ particles. The SEM image of $\mathrm{Cu}_{0.2}, \mathrm{Cu}_{2}$ and $\mathrm{Cu}_{7}$ particles are shown below for reference. The inset shows a schematic representation for estimation of motility (in A, $\mathrm{B}$, and $\mathrm{C}$ ) and VCL (in D, E, and F), respectively. The significance level was set at: **** $(\mathrm{P}<0.0001) ; * * *(\mathrm{P}<0.001) ; * *(\mathrm{P}<0.01)$; $^{*}(\mathrm{P}<0.05)$; n.s (statistically non-significant $)$. Scale bar: $2 \mu \mathrm{m}$

the smaller $\mathrm{Cu}$ particles. The cells are comparatively more motile at similar concentration ranges. The motility drops to $53 \%$ at $0.1 \mathrm{gL}^{-1}$ concentration of $\mathrm{Cu}$, to $32 \%$ at $0.5 \mathrm{~g} \mathrm{~L}^{-1}$ and to $26 \%$ at $1 \mathrm{~g} \mathrm{~L}^{-1}$ concentration compared to the control during the ${ }^{s t}$ interval. In the $\mathrm{II}^{\text {nd }}$ interval, the motility gets further reduced to $12 \%$ at $0.1 \mathrm{~g} \mathrm{~L}^{-1}$, to $7 \%$ at $0.5 \mathrm{~g} \mathrm{~L}^{-1}$, and completely diminishes at $1 \mathrm{~g} \mathrm{~L}^{-1}$ concentration of $\mathrm{Cu}$. In the III ${ }^{r d}$ interval, the sperm sample with the lowest concentration of $\mathrm{Cu}$ show some motility but it is not even $1 \%$ compared to its control.

With $\mathrm{Cu}_{7}$ particles, a not so prominent decrease in the sperm motility was noted. At 
the highest $\mathrm{Cu}$ concentration $\left(1 \mathrm{~g} \mathrm{~L}^{-1}\right)$ and highest incubation time (III ${ }^{r d}$ interval) still $38 \%$ sperm cells were found to be motile compared to the control (see Figure 4C). As there was not such a drastic decrease in sperm motility even at the highest $\mathrm{Cu}$ concentration, the experiments with lower concentrations were not performed.

The effectiveness of the $\mathrm{Cu}_{0.2}$ over $\mathrm{Cu}_{2}$ and $\mathrm{Cu}_{7}$ particles can be correlated to the amount of $\mathrm{Cu}^{2+}$ ions liberated by the $\mathrm{Cu}$ particles in the SP-TALP. As the size of the particle decreases, more amount of $\mathrm{Cu}^{2+}$ ions are released in the medium (see "Amount of copper ions released in aqueous media" in results and discussion section) and it is more effective in inhibiting sperm viability.

The curvilinear velocities (VCL) of the sperm cells lie in the range of $60 \mu \mathrm{ms}^{-1}$ to $120 \mathrm{\mu ms}^{-1}$. With the $\mathrm{Cu}$ particles of different size ranges and concentrations, the motile sperm maintained their velocity within this velocity range, a convincing trend is hard to predict. There was a slight decrease in the velocity compared to the control, for instance, in the case of $\mathrm{Cu}_{0.2}$ particles, (see Figure 4D), the velocity decreases by $15 \%$ in $\mathrm{I}^{s t}$ interval and by $34 \%$ in the $\mathrm{II}^{\text {nd }}$ interval compared to the control. A similar decreasing trend was observed for $\mathrm{Cu}_{2}$ particles (see Figure $4 \mathrm{E}$ ) in the $\mathrm{I}^{s t}$ interval and for $\mathrm{Cu}_{7}$ particles in $\mathrm{I}^{s t}$ and III $^{r d}$ interval (see Figure $4 \mathrm{~F}$ ). Although this decrease was not consistent and the presence of copper particles might not influence the velocity of the motile sperms. The VAP (average path velocity) and VSL (straight line velocity) show a similar trend to the VCL and are plotted in SI Figure S2.

\section{Conclusion}

Copper particles of three different sizes were synthesized by assisted polyol method. ${ }^{46}$ When these particles were incubated with bovine spermatozoa they showed inhibiting effects on sperm motility, which was studied in vitro. The inhibition efficiency varied with concentration and incubation time with the sperm cells and a strong size-dependent inhibition of 
sperm cell motility was noted, with the smaller particles being more effective inhibitors compared to the larger ones. The $\mathrm{Cu}^{2+}$ ions are known to be responsible for the immobilization of sperm cells, ${ }^{25}$ thus the extent of release of $\mathrm{Cu}^{2+}$ ions is correlated to the particle size by spectrophotometry and ICP-OES in both, water and SP-TALP. Additionally, SP-TALP favors an increased dissolution of metallic microparticles, releasing more $\mathrm{Cu}^{2+}$ ions, which is probably due to the presence of complexing proteins and bases in the medium. Therein, spectrophotometry was found to be less reliable for quantification of copper ions in complex media compared to ICP-OES.

Nano/microparticles are characterized by a high surface to volume ratio, which favors a rapid dissolution of ions from the copper particles. This is one of the main advantages of using nano/microparticles compared to macroscopic copper structures. Besides this sizedependent effect, another large benefit compared to traditional hormonal contraceptives is the reduced burden on waste water systems. It is well studied that the influx of hormones and their metabolites have drastic effects on aquatic systems ${ }^{9,11}$ and eventually human lives. ${ }^{13}$

The immobilization of bovine spermatozoa by copper microparticles has been demonstrated and such particles prove to be very useful components for prospective use in lubricants or as spermicidal agents for male contraception. In future studies, besides the biocompatibility of this approach, the compatibility of the here presented materials needs to be evaluated in combination with lubricants and potentially with latex, before proceeding to clinical tests.

\section{Acknowledgement}

We acknowledge a Freigeist grant (No 91619) from the Volkswagen foundation. P.C acknowledges the free state of Saxony represented by the state parliament for Saxony Fellowship. V.M. acknowledges the Humboldt Foundation for the Feodor-Lynen Fellowship. 


\section{Supporting Information Available}

The supporting info is available online and contains

- Supporting video

- Synthesis of $\mathrm{Cu}_{2}$ particles.

- Zeta-potential measurement.

- Average (VAP) and linear velocity (VSL) of the sperm cells under different experimental conditions.

\section{References}

(1) Anderson, R. A.; Baird, D. T. Male Contraception. Endocrine Reviews 2002, 23, 735762.

(2) Ross, J.; Hardee, K. Use of male methods of contraception worldwide. Journal of Biosocial Science 2017, 49, 648-663.

(3) Sabatini, R.; Cagiano, R.; Rabe, T. Adverse effects of hormonal contraception. Journal für Reproduktionsmedizin und Endokrinologie-Journal of Reproductive Medicine and Endocrinology 2011, 8, 130-156.

(4) Page, S. T.; Amory, J. K.; Bremner, W. J. Advances in male contraception. Endocrine Reviews 2008, 29, 465-493.

(5) Amory, J. K.; Page, S. T.; Bremner, W. J. Drug insight: recent advances in male hormonal contraception. Nature Clinical Practice Endocrinology $\& 6$ Metabolism 2006, 2, 32-41.

(6) Thirumalai, A.; Page, S. T. Recent developments in male contraception. Drugs 2019, 79, 11-20. 
(7) Runnalls, T. J.; Beresford, N.; Losty, E.; Scott, A. P.; Sumpter, J. P. Several synthetic progestins with different potencies adversely affect reproduction of fish. Environmental Science \& Technology 2013, 47, 2077-2084.

(8) Owen, R.; Jobling, S. The hidden costs of flexible fertility. Nature 2012, 485, 441-441.

(9) Kidd, K. A.; Blanchfield, P. J.; Mills, K. H.; Palace, V. P.; Evans, R. E.; Lazorchak, J. M.; Flick, R. W. Collapse of a fish population after exposure to a synthetic estrogen. Proceedings of the National Academy of Sciences 2007, 104, 8897-8901.

(10) Anway, M. D.; Cupp, A. S.; Uzumcu, M.; Skinner, M. K. Epigenetic transgenerational actions of endocrine disruptors and male fertility. Science 2005, 308, 1466-1469.

(11) Aris, A. Z.; Shamsuddin, A. S.; Praveena, S. M. Occurrence of $17 \alpha$-ethynylestradiol (EE2) in the environment and effect on exposed biota: a review. Environment International 2014, 69, 104-119.

(12) Fent, K. Progestins as endocrine disrupters in aquatic ecosystems: concentrations, effects and risk assessment. Environment International 2015, 84, 115-130.

(13) Adeel, M.; Song, X.; Wang, Y.; Francis, D.; Yang, Y. Environmental impact of estrogens on human, animal and plant life: a critical review. Environment International 2017, 99, 107-119.

(14) Mansour, D.; Inki, P.; Gemzell-Danielsson, K. Efficacy of contraceptive methods: a review of the literature. The European Journal of Contraception $\&$ Reproductive Health Care 2010, 15, 4-16.

(15) Wang, H.; Chen, X.-X.; Wang, L.-R.; Mao, Y.-D.; Zhou, Z.-M.; Sha, J.-H. AF-2364 is a prospective spermicide candidate. Asian Journal of Andrology 2010, 12, 322-335.

(16) Guha, S. K.; Singh, G.; Anand, S.; Ansari, S.; Kumar, S.; Koul, V. Phase I clinical trial of an injectable contraceptive for the male. Contraception 1993, 48, 367-375. 
(17) Guha, S. K.; Singh, G.; Ansari, S.; Kumar, S.; Srivastava, A.; Koul, V.; Das, H.; Malhotra, R.; Das, S. Phase II clinical trial of a vas deferens injectable contraceptive for the male. Contraception 1997, 56, 245-250.

(18) De Quatrefages, M. Expériences sur la Fécondation Artificielle des CEufs de Hermelle et de Taret. Annales des Sciences Naturelles 1850, 13, 126-140.

(19) von Studnitz, W.; Berezin, D. Studies on serum copper during pregnancy, during the menstrual cycle, and after the administration of oestrogens. European Journal of Endocrinology 1958, 27, 245-252.

(20) Keil, H.; Nelson, V. The Rôle of Copper in Hemoglobin Regeneration and in Reproduction. Journal of Biological Chemistry 1931, 93, 49-57.

(21) Hart, E.; Steenbock, H.; Waddell, J.; Elvehjem, C., et al. Iron in nutrition VII. Copper as a supplement to iron for hemoglobin building in the rat. Journal of Biological Chemistry 1928, 77, 797-812.

(22) Fevold, H.; Hisaw, F.; Greep, R. Augmentation of the gonad stimulating action of pituitary extracts by inorganic substances, particularly copper salts. American Journal of Physiology-Legacy Content 1936, 117, 68-74.

(23) Knazicka, Z.; Tvrda, E.; Bardos, L.; Lukac, N. Dose-and time-dependent effect of copper ions on the viability of bull spermatozoa in different media. Journal of Environmental Science and Health, Part A 2012, 47, 1294-1300.

(24) Oster, G.; Salgo, M. P. Copper in mammalian reproduction. Advances in Pharmacology 1977, 14, 327-409.

(25) Maynard, P.; Elstein, M.; Chandler, J. The effect of copper on the distribution of elements in human spermatozoa. Reproduction 1975, 43, 41-48. 
(26) Skandhan, K. Review on copper in male reproduction and contraception. Revue française de gynécologie et d'obstétrique 1992, 87, 594-598.

(27) Ortiz, M. E.; Croxatto, H. B.; Bardin, C. W. Mechanisms of action of intrauterine devices. Obstetrical \&3 Gynecological Survey 1996, 51, 42S-51S.

(28) Thiery, M. Pioneers of the intrauterine device. The European Journal of Contraception \& Reproductive Health Care 1997, 2, 15-23.

(29) Zipper, J. A.; Tatum, H. J.; Pastene, L.; Medel, M.; Rivera, M. Metallic copper as an intrauterine contraceptive adjunct to the "T" device. American Journal of Obstetrics and Gynecology 1969, 105, 1274-1278.

(30) Tatum, H. J. Metallic copper as an intrauterine contraceptive agent. American Journal of Obstetrics and Gynecology 1973, 117, 602-618.

(31) Zipper, J.; Medel, M.; Prager, R. Suppression of fertility by intrauterine copper and zinc in rabbits. A new approach to intrauterine contraception. American Journal of Obstetrics and Gynecology 1969, 105, 529-534.

(32) Mishell, D. R. Intrauterine devices: mechanisms of action, safety, and efficacy. Contraception 1998, 58, 45S-53S.

(33) Orlans, F. B. Copper IUDs: a review of the literature. Contraception 1974, 10, 543-559.

(34) Carrascosa, J. P.; Cotán, D.; Jurado, I.; Oropesa-Ávila, M.; Sánchez-Martín, P.; Savaris, R. F.; Tan, J.; Sánchez-Alcázar, J. A.; Tan, S. L.; Horcajadas, J. A. The Effect of Copper on Endometrial Receptivity and Induction of Apoptosis on Decidualized Human Endometrial Stromal Cells. Reproductive Sciences 2017, 25, 985-999.

(35) Skandhan, K. Copper: a possible male contraceptive. Advances in Contraceptive Delivery Systems: CDS 1988, 4, 37-40. 
(36) Ahsan, R. K.; Farooq, A.; Kapur, M.; Laumas, K. Effect of intravasal copper on the fertility of rats. Reproduction 1976, 48, 271-274.

(37) Kapur, M.; Mokkapati, S.; Farooq, A.; Ahsan, R.; Laumas, K. Copper intravas device (IVD) and male contraception. Contraception 1984, 29, 45-54.

(38) Skandhan, K. Development of copper male contraceptive. Contribution of India. Panminerva Medica 1993, 35, 52-56.

(39) Heath, J. R. Nanotechnologies for biomedical science and translational medicine. Proceedings of the National Academy of Sciences 2015, 112, 14436-14443.

(40) Sonntag, L.; Simmchen, J.; Magdanz, V. Nano-and micromotors designed for cancer therapy. Molecules 2019, 24, 3410.

(41) McNamara, K.; Tofail, S. A. Nanoparticles in biomedical applications. Advances in Physics: X 2017, 2, 54-88.

(42) Li, W.-q.; Sun, C.-y.; Wang, F.; Wang, Y.-c.; Zhai, Y.-w.; Liang, M.; Liu, W.-j.; Liu, Z.m.; Wang, J.; Sun, F. Achieving a new controllable male contraception by the photothermal effect of gold nanorods. Nano Letters 2013, 13, 2477-2484.

(43) Ding, W.; Chen, Z.; Gu, Y.; Chen, Z.; Zheng, Y.; Sun, F. Magnetic Testis Targeting and Magnetic Hyperthermia for Noninvasive, Controllable Male Contraception via Intravenous Administration. Nano Letters 2021, 21, 6289-6297.

(44) Bao, W.; Xie, L.; Zeng, X.; Kang, H.; Wen, S.; Cui, B.; Li, W.; Qian, Y.; Wu, J.; Li, T., et al. A cocktail-inspired male birth control strategy with physical/chemical dual contraceptive effects and remote self-cleared properties. ACS Nano 2019, 13, 1003-1011.

(45) Ball, P. Nano contraception. Nature Materials 2013, 12, 602-602. 
(46) Chattopadhyay, P.; Gemming, T.; Eychmüller, A.; Simmchen, J. Polyol-Assisted Synthesis of Copper Particles. The Journal of Physical Chemistry C 2021, 125, 2488724893.

(47) Al-Hakkani, M. F. Biogenic copper nanoparticles and their applications: A review. $S N$ Applied Sciences 2020, 2, 1-20.

(48) Wilson-Leedy, J.; Ingermann, R. Computer assisted sperm analysis using ImageJ; description of necessary components and use of free software. Idaho 2011, 1-7.

(49) Amann, R. P.; Waberski, D. Computer-assisted sperm analysis (CASA): capabilities and potential developments. Theriogenology 2014, 81, 5-17.

(50) Wen, T.; Qu, F.; Li, N. B.; Luo, H. Q. A facile, sensitive, and rapid spectrophotometric method for copper (II) ion detection in aqueous media using polyethyleneimine. Arabian Journal of Chemistry 2017, 10, S1680-S1685.

(51) Magdanz, V.; Gebauer, J.; Sharan, P.; Eltoukhy, S.; Voigt, D.; Simmchen, J. Spermparticle interactions and their prospects for charge mapping. Advanced Biosystems 2019, 3, 1900061.

(52) Magdanz, V.; Khalil, I. S.; Simmchen, J.; Furtado, G. P.; Mohanty, S.; Gebauer, J.; Xu, H.; Klingner, A.; Aziz, A.; Medina-Sánchez, M., et al. IRONSperm: Spermtemplated soft magnetic microrobots. Science Advances 2020, 6, 1-15.

(53) Holland, M.; White, I. Heavy metals and human spermatozoa: II. The effect of seminal plasma on the toxicity of copper metal for spermatozoa. International Journal of Fertility 1982, 27, 95-99.

(54) Roy, D.; Dey, S.; Majumder, G. C.; Bhattacharyya, D. Copper: a biphasic regulator of caprine sperm forward progression. Systems Biology in Reproductive Medicine 2014, $60,52-57$. 
(55) Roblero, L.; Guadarrama, A.; Lopez, T.; Zegers-Hochschild, F. Effect of copper ion on the motility, viability, acrosome reaction and fertilizing capacity of human spermatozoa in vitro. Reproduction, Fertility and Development 1996, 8, 871-874.

(56) Rivas, B. L.; Pooley, S. A.; Pereira, E. D.; Cid, R.; Luna, M.; Jara, M. A.; Geckeler, K. E. Water-soluble amine and imine polymers with the ability to bind metal ions in conjunction with membrane filtration. Journal of Applied Polymer Science 2005, 96, 222-231. 
Graphical TOC Entry

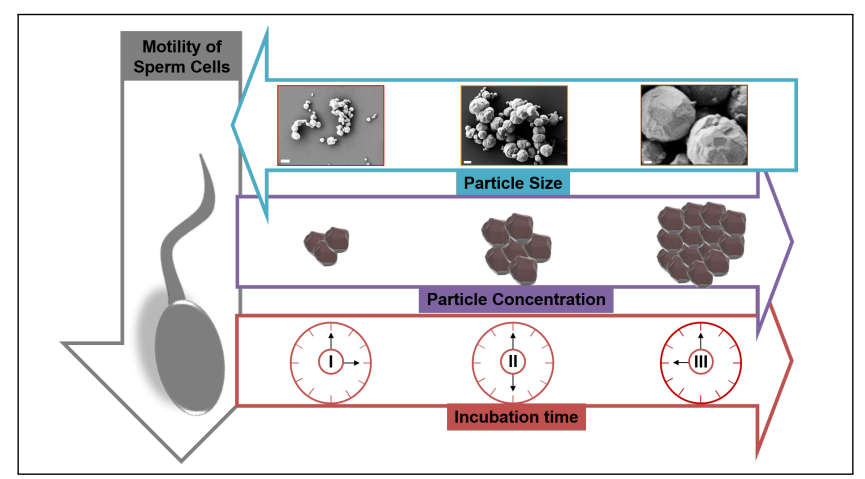

